\section{Root Morphology and Number of Canals in Mandibular Central and Lateral Incisors Using Cone Beam Computed Tomography}

Samira Saati ${ }^{1}$, Abbas Shokri ${ }^{1}$, Maryam Foroozandeh${ }^{1}$, Jalal Poorolajal², Nooshin Mosleh ${ }^{1}$
'Department of Oral and Maxillofacial Radiology, Dental School, Hamadan University of Medical Sciences, Hamadan, Iran ${ }^{2}$ Department of Epidemiology, School of Public Health, Hamadan University of Medical Sciences, Hamadan, Iran

Correspondence: Maryam Foroozandeh, Shahid Fahmideh Blvd, in front of Mardom Park, 6516647447 Hamadan, Iran. Tel: +98-918-4400791. e-mail: f.maryam1991@yahoo.com

\begin{abstract}
Most failures in endodontic treatment of mandibular incisors are due to the presence of a missed canal specifically the lingual. This investigation aimed to examine the root morphology and number of canals in mandibular incisors using cone beam computed tomography (CBCT). Two hundred and seven patients were assessed in terms of their mandibular central and lateral incisors of CBCT. The inclusion criteria were absence of root resorption, coronal restoration or root filling and clarity and optimal resolution of images. According to the Vertucci's classification, number of roots and canals and type of canal were evaluated by two oral and maxillofacial radiologists. In order to data analysis SPSS version 16 and descriptive statistics were implemented. All mandibular incisors had one root. Most central (84.5\%) and lateral (78.2\%) incisors had a single canal $(p=0.065)$. The majority of central (54.5\%) and lateral (56.5\%) incisors were Vertucci's type I ( $p=$ 0.102). Prevalence of one canal in males: central (84.8\%), lateral (77.9\%) and in females: central $(84.2 \%)$, lateral $(78.5 \%)(p=0.518)$. Prevalence of Vertucci's type I in males: central $(52.3 \%)$, lateral $(45.3 \%)$ and in females: central $(56.1 \%)$, lateral $(64.4 \%)(p=0.188)$. The prevalence of two canals was $15.5 \%$ (central) and $21.8 \%$ (lateral) in mandibular incisors. The Vertucci's type I was the most typical kinds of mandibular incisors. Considering the limitations of periapical radiography in determining canal morphology, CBCT can be helpful in case of any concern regarding root canal morphology.
\end{abstract}

Key Words: morphology, root canal, mandibular central incisor, mandibular lateral incisor, conebeam computed tomography.

\section{Introduction}

Teeth with irreversible pulpitis can be preserved by endodontic treatment (1). In endodontic treatment, some root canals may remain undetected due to inadequate knowledge about root canal anatomy or insufficient investigations on additional canals. Finding additional canals and adequately filling them significantly improves the prognosis of treatment (2). Several apical foramina, loops, C-shaped canals and accessory canals have been reported in teeth (3). Single-canal mandibular incisors have a wide range of prevalence in different populations due to anatomical variations. Mandibular anterior teeth mainly have one root and one canal. A small percentage of these teeth may have two roots or two canals (4). One previous study reported the prevalence of two canals to be 7.6\% for central and $4.17 \%$ for lateral incisors (5). Some other root canal morphologies have also been reported. In one reported type, two separate canals extend from the pulp chamber to mid-root where the lingual canal branches into two canals. The three canals join in the apical third and ending one single apical foramen. In another type, one canal extends from the pulp chamber, divides into two canals in the middle third of the root and the two canals join to form one canal again. The canal branches again into three separate canals with distinct apical foramina (3).

Several methods such as tooth sectioning, computed tomography (CT) scan, clearing technique and dyes are used for assessment of root canal morphology in vitro (6). Cone beam computed tomography (CBCT) is one suggested technique to determine root canal morphology. The use of CBCT imaging in endodontics should be limited to the assessment and treatment of complex endodontic conditions, such as the following: Identification of potential accessory canals in teeth with suspected complex morphology, Identification of root canal system anomalies and determination of root curvature, Diagnosis of dental periapical pathosis in patients who present with contradictory or nonspecific clinical signs and symptoms or conventional radiographic findings, Diagnosis of pathosis of nonendodontic origin, Intraoperative or postoperative assessment of endodontic treatment complications, Diagnosis and management of dentoalveolar trauma, Localization and differentiation of external from internal root resorption or invasive cervical resorption, Pre-surgical case planning to determine the exact location of root apex or apices and to evaluate the proximity of adjacent anatomic structures (7). 
$\mathrm{CBCT}$ is superior to conventional $\mathrm{CT}$ since it has excellent resolution (smaller than millimeter scale) and much lower patient radiation dose (8). CBCT scans can better visualize additional canals compared to other modalities such as digital radiography and cross-sectioning (9). Considering the significance of adequate knowledge about root morphology and number of canals in mandibular central and lateral incisors, and also to increase the success of endodontic treatment and decrease procedural errors, the current study aimed at exploring the root morphology and number of canals in mandibular central and lateral incisors on CBCT scans of patients.

\section{Material and Methods}

\section{Patients}

This case-control study was conducted on CBCT scans of 207 patients presenting to the Radiology Department of Hamadan University, School of Dentistry to evaluate the morphology of their mandibular central and lateral incisors. These patients required CBCT scans for reasons except those mentioned in this study such as evaluation of bone volume prior to implant placement, examination of root apex and its relationship with important anatomical structures prior to periapical surgery, detection of dentoalveolar trauma, tumors, tooth fracture, position of impacted teeth prior to orthodontic treatment and assessment of symptomatic teeth after endodontic treatment. In absence of optimal clarity or presence of root resorption, coronal restoration, root filling or anomalies or lesions in the anterior mandible, the radiographs were excluded from the study (10).

\section{CBCT Scans}

Images were obtained by a CBCT scanner (NewTom, Verona, Italy) with exposure settings of $110 \mathrm{kV}, 0.3-2 \mathrm{~mA}$, 2.5-6.7 $\mathrm{mA}$ range, scanning time of $<12$ seconds, field of view of 6.6inch or 9.9inch or 12.12inch, voxel size of 0.25 $\mathrm{mm}$, axial thickness of $0.25 \mathrm{~mm}$ and radiation dose of $0.2-$ $2.2 \pm 30 \% \mathrm{mGy}$; images were obtained in DICOM format and reconstructed in axial, cross-sectional and sagittal planes with $1 \mathrm{~mm}$ thickness and $1 \mathrm{~mm}$ interval.

\section{Evaluation of Images}

Two oral and maxillofacial radiologists evaluated the images. To ensure reliability of the tool, the intra-class correlation coefficient was calculated. Images were viewed using the software NNT Viewer (NNT Software Corporation, Yokohama, Japan) on a 17-inch monitor (L1752SE Series, LG Corporations, South Korea) with a resolution of $1280 \times 1024$ pixels in a dark room. Images were evaluated on axial and cross-sectional planes. On the axial plane, roots were evaluated by scrolling the plane. In order to more accurately inspect some scans, cross-sectional planes with
$30 \mathrm{~mm}$ width and $0.5 \mathrm{~mm}$ thickness were used. Number of roots, number of canals and type of canal according to the Vertucci's classification were determined (11).

The Vertucci's classification is as follows: Type I: One single canal extending from the pulp chamber; Type II: Two separate canals extend from the pulp chamber and merge into one canal before reaching the apex; Type III: One canal extends from the pulp chamber and branches into two canals, which later merge at the apical foramen; Type IV: Two separate canals extend from the pulp chamber to the apex; Type V: One canal leaves the pulp chamber and divides into two separate canals with distinct apical foramina; Type VI: Two separate canals leave the pulp chamber, merge at the mid-root and then branch again into two separate canals; Type VII: One canal leaves the pulp chamber and branches into two canals, which merge again at the mid-root and then branch again into two separate canals at the apex; Type VIII: Three distinct canals leave the pulp chamber and extend to the apex.

Number of roots was determined on the axial plane according to a study by Pecora (12) in 1992 as follows: Single-rooted teeth: Teeth with one distinct root or two distinct canals, which appear as two roots but they are fused. Multi-rooted teeth: Teeth with branched roots (partially or completely), teeth with three separate roots or branching at any level below the pulp chamber.

Data were analyzed using SPSS version 16 and descriptive statistics.

\section{Results}

A total of 207 CBCT scans of patients were evaluated. Of patients, 86 were males and 121 were females. The intra-class correlation coefficient was calculated to assess the agreement between the first and second observers and was found to be $86 \%$. This value was acceptable.

All mandibular central and lateral incisors were singlerooted. Also, 85.9\% of mandibular right central incisors, $83.1 \%$ of mandibular left central incisors and a total of $84.5 \%$ of all mandibular central incisors had one canal. Moreover, $80.6 \%$ of mandibular right lateral incisors, $75.8 \%$ of mandibular left lateral incisors and a total of $78.2 \%$ of all mandibular lateral incisors had one canal $(p=0.065)$. Totally, $84.8 \%$ of mandibular central incisors of males and $84.2 \%$ of mandibular central incisors of females had one canal. Also, 77.9\% of mandibular lateral incisors of males and $78.5 \%$ of mandibular lateral incisors of females had one canal ( $p=0.518$ ) (Table 1) (Figs. 1,2).

According to the Vertucci's classification, $55.1 \%$ of mandibular right central incisors, $54.1 \%$ of mandibular left central incisors and $54.5 \%$ of all mandibular central incisors were Vertucci's type I. Also, 60.8\% of mandibular right lateral incisors, 52.1\% of mandibular left lateral 
incisors and $56.5 \%$ of all mandibular lateral incisors were Vertucci's type I. Moreover, $52.3 \%$ of mandibular central incisors of males and $56.1 \%$ of mandibular central incisors of females were type I. Moreover, 45.3\% of mandibular lateral incisors of males and $64.4 \%$ of mandibular lateral incisors of females were Vertucci's type I $(p=0.188)$ (Table 2).

\section{Discussion}

Epidemiological characters of each population and

Table 1. Number of canals in mandibular central and lateral incisors on CBCT scans based on the side of the jaw and sex

\begin{tabular}{lcccc}
\hline \multirow{2}{*}{$\begin{array}{c}\text { Tooth } \\
\text { type }\end{array}$} & \multicolumn{3}{c}{ Number of canals } \\
\cline { 3 - 5 } Right side & Central & $178(85.9 \%)$ & $29(14.1 \%)$ & $207(100)$ \\
& Lateral & $167(80.6 \%)$ & $40(19.4 \%)$ & $207(100 \%)$ \\
\multirow{2}{*}{ Left side } & Central & $172(83.1 \%)$ & $35(16.9 \%)$ & $207(100 \%)$ \\
& Lateral & $157(75.8 \%)$ & $50(24.2 \%)$ & $207(100 \%)$ \\
\multirow{2}{*}{ Total } & Central & $175(84.5 \% \%)$ & $32(15.5 \%)$ & $207(100)$ \\
& Lateral & $162(78.2 \%)$ & $45(21.8 \%)$ & $207(100 \%)$ \\
\multirow{2}{*}{ Male } & Central & $73(84.8 \%)$ & $13(15.2 \%)$ & $86(100 \%)$ \\
& Lateral & $67(77.9 \%)$ & $18(21.1 \%)$ & $86(100 \%)$ \\
\multirow{2}{*}{ Female } & Central & $102(84.2 \%)$ & $19(15.8 \%)$ & $121(100 \%)$ \\
& Lateral & $95(78.5 \%)$ & $26(21.5 \%)$ & $121(100 \%)$ \\
\multirow{2}{*}{ Total } & Central & $175(84.5 \%)$ & $32(15.5 \%)$ & $207(100 \%)$ \\
& Lateral & $164(78.2 \%)$ & $45(21.8 \%)$ & $207(100 \%)$
\end{tabular}

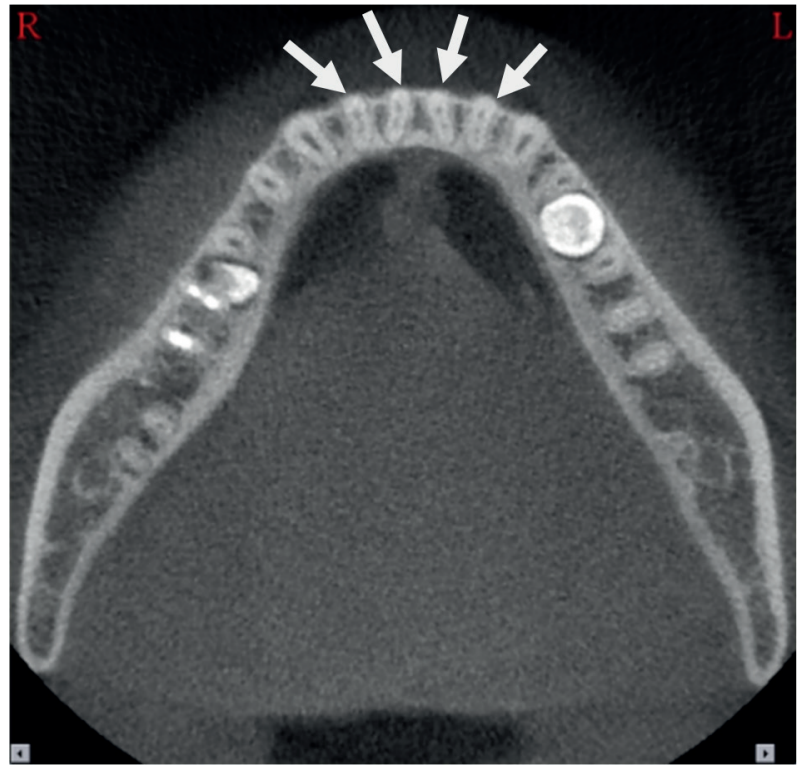

Figure 1. Mandibular incisors with two canals on axial view on CBCT image. ethics should be evaluated. Knowledge and understanding the status can lead to an increase of successful treatment. Knowledge about the common root canal morphology and its' variations is a prerequisite for a successful endodontic treatment. Presence of a missed canal, especially a lingual canal, is among the most important causes of endodontic treatment failure in mandibular incisors. The first step in endodontic treatment of teeth is acquiring knowledge about root canal anatomy. Also, prior to access cavity preparation, the clinician must well study the radiographs taken at different angles. Noticing a sudden narrowing or attenuation in the canal path on parallel periapical radiographs may indicate possible presence of canal bifurcation. If only one of the existing two canals is treated, pulp tissue of the second canal becomes necrotic and produces toxic agents, which can reach the periodontal ligament via an accessory or lateral canal. Clinicians must always consider the presence of a bifurcated canal in mandibular incisors and further remove the lingual part of the pulp chamber roof to access the lingual canal. For a successful endodontic treatment in these teeth, the access cavity must be extended incisogingivally. Also, the lingual part of the pulp chamber should be adequately widened and lingual shelf of dentin over the second (lingual) canal must be removed $(10,13)$. Adequate knowledge about the internal anatomy of the teeth and observation of radiographs can help determine the canal morphology and perform a successful treatment. None of the commonly used

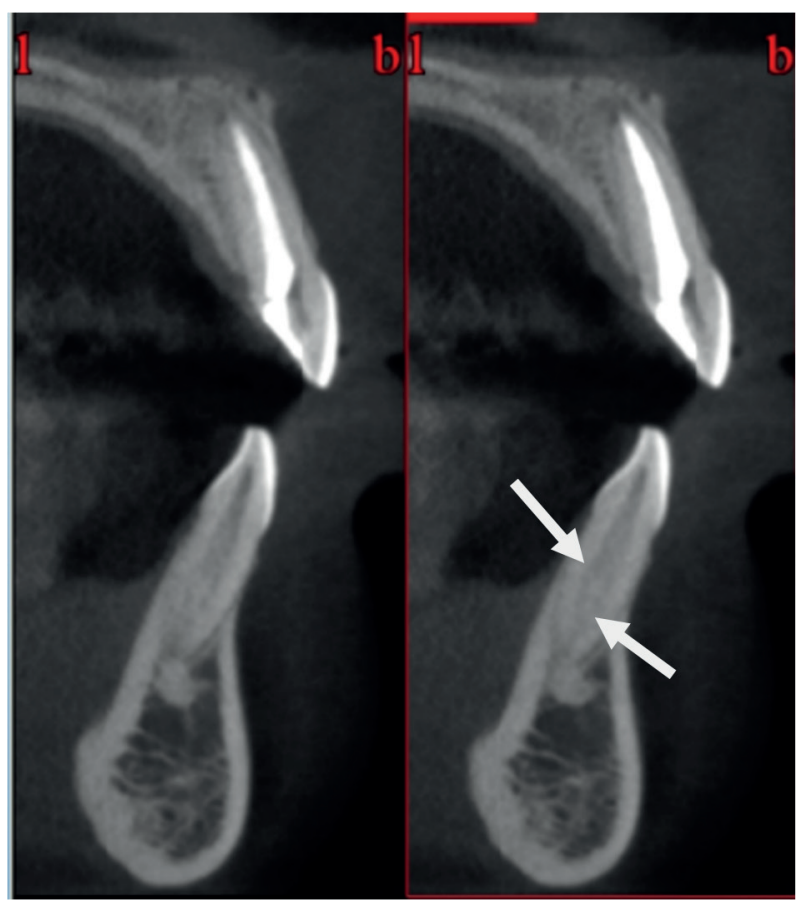

Figure 2. Mandibular incisor with two canals on cross-sectional CBCT image. 
methods for assessment of internal root canal anatomy such as coloring of canals and clearing technique, conventional radiography, digital radiography or computed tomography can serve as the gold standard for this purpose because of their inherent limitations (14).

Detection of anatomical complexities on periapical radiographs may be difficult even for experienced dentists and may lead to misdiagnosis due to the $2 \mathrm{D}$ nature of periapical radiography. In this study, CBCT was used for assessment of the root canals of mandibular incisors. Based on our findings, CBCT can be beneficial for determination of root canal morphology. Similar to our findings, Assadian et al. (9) stated that CBCT analyses revealed higher number of teeth with multiple root canals compared to other techniques.
In the present study, all mandibular central and lateral were single-rooted. Al-Qudah and Awawdeh (15) reported that all central and lateral had one single root in their study, which was in line with ours. According to Kayaoglu et al. (4) The majority of mandibular anterior teeth have one root and one canal and mandibular canine teeth had a higher prevalence $(3.1 \%)$ of two roots compared to central and lateral.

In this paper, most mandibular central $(85.9 \%$ in the right side, $83.1 \%$ in the left side and $84.5 \%$ in total) and lateral $(80.6 \%$ in the right side, $75.8 \%$ in the left side and $78.2 \%$ in total) incisors had one canal, which was in agreement with the results of Boruah and Bhuyan (16) (64\% of mandibular incisors), Shemesh et al. (17) (59.5\% of mandibular central and $62.1 \%$ of mandibular lateral

Table 2. Canal type of mandibular central and lateral incisors according to the Vertucci's classification on CBCT scans based on the side of jaw and sex

\begin{tabular}{|c|c|c|c|c|c|c|c|c|}
\hline \multirow{2}{*}{ Side } & \multirow{2}{*}{ Tooth type } & & \multicolumn{6}{|c|}{ Vertucci's classification } \\
\hline & & & Type I & Type II & Type III & Type IV & Type V & Total \\
\hline \multirow{4}{*}{ Right side } & \multirow{2}{*}{ Central } & Number & 114 & - & 69 & - & 24 & 207 \\
\hline & & Percentage & 55.1 & - & 34.4 & - & 11.5 & 100 \\
\hline & \multirow{2}{*}{ Lateral } & Number & 126 & - & 54 & - & 27 & 207 \\
\hline & & Percentage & 60.8 & - & 26.1 & - & 13.1 & 100 \\
\hline \multirow{4}{*}{ Left side } & \multirow{2}{*}{ Central } & Number & 112 & - & 73 & & 22 & 207 \\
\hline & & Percentage & 54.1 & - & 35.2 & - & 10.7 & 100 \\
\hline & \multirow{2}{*}{ Lateral } & Number & 108 & - & 54 & - & 45 & 207 \\
\hline & & Percentage & 52.1 & - & 26.1 & - & 21.8 & 100 \\
\hline \multirow{4}{*}{ Total } & \multirow{2}{*}{ Central } & Number & 113 & - & 71 & - & 23 & 207 \\
\hline & & Percentage & 54.5 & - & 34.2 & - & 11.3 & 100 \\
\hline & \multirow{2}{*}{ Lateral } & Number & 117 & - & 54 & - & 36 & 207 \\
\hline & & Percentage & 56.5 & - & 26.1 & - & 17.4 & 100 \\
\hline \multirow{4}{*}{ Male } & \multirow{2}{*}{ Central } & Number & 45 & - & 30 & - & 11 & 86 \\
\hline & & Percentage & 52.3 & - & 34.8 & - & 12.9 & 100 \\
\hline & \multirow{2}{*}{ Lateral } & Number & 39 & - & 31 & - & 14 & 86 \\
\hline & & Percentage & 45.3 & - & 36.1 & - & 18.6 & 100 \\
\hline \multirow{4}{*}{ Female } & \multirow{2}{*}{ Central } & Number & 68 & - & 41 & - & 12 & 121 \\
\hline & & Percentage & 56.1 & - & 33.8 & - & 10.1 & 100 \\
\hline & \multirow{2}{*}{ Lateral } & Number & 78 & - & 23 & - & 22 & 121 \\
\hline & & Percentage & 64.4 & - & 19.1 & - & 16.5 & 100 \\
\hline \multirow{4}{*}{ Total } & \multirow{2}{*}{ Central } & Number & 113 & - & 71 & - & 23 & 207 \\
\hline & & Percentage & 54.5 & - & 34.2 & - & 11.3 & 100 \\
\hline & \multirow{2}{*}{ Lateral } & Number & 117 & - & 54 & - & 36 & 207 \\
\hline & & Percentage & 56.5 & - & 26.1 & - & 17.4 & 100 \\
\hline
\end{tabular}


incisors), da Silva et al. (18) (64.5\% of mandibular central \&t $60.5 \%$ of mandibular lateral incisors), Al-Qudah and Awawdeh (15) (73.8\% of mandibular central incisors), Kayaoglu et al. (4) (82.8\% of lateral incisors) and Han et al. (19) (72.64\% of mandibular lateral incisors). In contrast to the findings of this paper, Saberi et al. (10) (66\%) and Ezoddini et al. (20) (55.9\%) reported that most mandibular incisors had two canals. Zhang et al. (21) reported the prevalence of central incisors with two canals to be 39\%; although only $8.8 \%$ had two separate apical foramina.

In the present investigation, based on Vertucci's classification, most mandibular central incisors (55.1\% in the right side, $54.1 \%$ in the left side and $54.5 \%$ in total) and the majority of mandibular lateral incisors $(60.8 \%$ in the right side, $52.1 \%$ in the left side and $56.5 \%$ in total) were type I, which was in line with the results of Assadian et al. (9) (43.4\% of mandibular incisors), Zhang et al. (21) (61\% of mandibular central incisors), Saberi et al. (20) (34\% of mandibular incisors) and Scarlatescu et al. (22) (65.6\% of mandibular incisors).

The above-mentioned results were in agreement with our findings. However, Assadian et al. stated that all three methods of evaluation(CBCT, Digital Radiography and Cross-Sectioning) showed that the majority of the samples had a single canal with Type I configuration according to Vertucci's classification, except for CBCT imaging which indicated Vertucci's Type III to be the most frequent anatomical configuration (9). Lin et al. (23) indicated that Vertucci's type III was the most common type among two-canal teeth.

In this examination, two-canal mandibular central and lateral incisors had almost the same prevalence in males and females ( $p=0.538)$, which was in line with the results of Sert and Bayirli (24).They found that among demographic variables, age and gender were correlated with two-canal roots. Although the prevalence of incisors with two root canals was the same in males and females in their study, two-canal mandibular canines were significantly more prevalent in females (24). Some studies found significant differences in prevalence of two-canal teeth between males and females (the prevalence of two canals in the mandibular anterior teeth was higher in males than in females) (25). Differences between the results of morphological studies may be due to variations of examination methods, classification systems, sample sizes and ethnic backgrounds of tooth sources.

Failure of endodontic treatment in mandibular incisors is mainly due to the presence of a missed canal especially a lingual canal. Thus, comprehensive knowledge about the internal anatomy and prevalence of two canals in these teeth is required for a successful endodontic treatment. Based on the results of this study, all mandibular incisors had one root. Most central (84.5\%) and lateral (78.2\%) incisors had a single canal $(p=0.065)$. The majority of central (54.5\%) and lateral (56.5\%) incisors were Vertucci's type I $(p=0.102)$. Prevalance of one canal in males: central $(84.8 \%)$, lateral $(77.9 \%)$ and in females: central $(84.2 \%)$, lateral (78.5\%) (Pvalue: 0.518). Prevalence of Vertucci's type I in males: central (52.3\%), lateral (45.3\%) and in females: central (56.1\%), lateral $(64.4 \%)(p=0.188)$. The prevalence of two canals was 15.5\% (central) and 21.8\% (lateral) in mandibular incisors. Also, the Vertucci's type I was the most common type in mandibular incisors. Regarding the limitations of periapical radiography in determining canal morphology, CBCT can be helpful in case of any concern regarding root canal morphology.

\section{Resumo}

A maioria das fal has no tratamento endodôntico dos incisivos mandibulares é devida à presença de um canal perdido, especificamente do lingual. Esta investigação teve como objetivo analisar a morfologia radicular e o número de canais nos incisivos inferiores utilizando a tomografia computadorizada de feixe cônico (TCFC). Duzentos e sete pacientes foram avaliados em termos de seus incisivos centrais e laterais mandibulares de TCFC. Os critérios de inclusão foram ausência de reabsorção radicular, restauração coronária ou preenchimento radicular e clareza e resolução ótima das imagens. De acordo com a classificação de Vertucci, o número de raizes e canais e o tipo de canal foram avaliados por dois radiologistas orais e maxilo-faciais. Para análise dos dados, o SPSS versão 16 e análise estatística descritiva foram implementados. Todos os incisivos inferiores tinham uma raiz. A maioria dos incisivos centrais $(84,5 \%)$ e laterais $(78,2 \%)$ apresentava um único canal (valor de $\mathrm{P}: 0,065)$. A maioria dos incisivos centrais $(54,5 \%)$ e laterais $(56,5 \%)$ eram do tipo I de Vertucci (valor de $P: 0,102)$. Prevalência de um canal no sexo masculino: central $(84,8 \%)$, lateral $(77,9 \%)$ e no feminino: central $(84,2 \%)$, lateral $(78,5 \%)$ (valor de P: $0,518)$. Prevalência de Vertucci tipo I em homens: central (52,3\%), lateral $(45,3 \%)$ e feminina: central $(56,1 \%)$, lateral $(64,4 \%)$ (valor de P: 0,188$)$. A prevalência de dois canais foi de 15,5\% (central) e 21,8\% (lateral) nos incisivos inferiores. 0 tipo I de Vertucci era dos tipos mais comuns de incisivos inferiores. Considerando as limitações da radiografia periapical na determinação da morfologia do canal, a TCFC pode ser útil em caso de qualquer preocupação com relação à morfologia do canal radicular.

\section{References}

1. Ingle Jl, Himel VT, Hawrish $\mathrm{CE}$, et al. Endodontic cavity preparation. In: Ingle JI,Bakland LK, (eds). Endodontic. 5 th. BC Decker inc 2002; 408470.

2. Versiani MA, Pécora JD, Sousa-Neto MD. The anatomy of two-rooted mandibular canines determined using micro-computed tomography. Int Endod J 2011;44:682-687.

3. Vertucci FJ. Root canal morphology and its relationship to endodontic procedures. Endod Topics 2005;10:3-29.

4. Kayaoglu G, Peker I, Gumusok M, Sarikir C, Kayadugun A, Ucok O. Root and canal symmetry in the mandibular anterior teeth of patients attending a dental clinic: CBCT study. Braz Oral Res 2015;29:1-7.

5. Zhao Y, Dong YT, Wang XY, Wang ZH, Li G, Liu MQ, et al. Cone-beam computed tomography analysis of root canal configuration of 4,674 mandibular anterior teeth. J PKU 2014;46:95-99.

6. Raj UJ, Mylswamy S. Root canal morphology of maxillary second premolars in an Indian population. J Conserv Dent 2010;13:148-151.

7. White SC, Pharoah MJ. Oral Radiology: Principles and Interpretation. 7th ed. USA: Mosby; 2014. p. 206.

8. Benington PC, Khambay BS, Ayoub AF. An overview of three- 
dimensional imaging in dentistry. Dent Update 2010;37:494-496.

9. Assadian H, Dabbaghi A, Gooran M, Eftekhar B, Sharifi S, Shams N, et al. Accuracy of CBCT, digital radiography and cross-sectioning for the evaluation of mandibular incisor root canals. Iran Endod J 2016;11:106110.

10. Ezoddini F, Mohammadi Z, Tabrizizadeh M. Root canal morphology of human mandibular incisors in Yazd province. Dent Res J 2006;3:1-3.

11. Vertucci FJ, Seelig A, Gillis R. Root canal morphology of the human maxillary second premolar. Oral Surg Oral Med Oral Pathol Oral Radiol Endodon 1974;38:456-464

12. Pecora JD, Saquy $P$, Sousa Neto $M$, Woelfel J. Root form and canal anatomy of maxillary first premolars. Braz Dent J 1991;2:87-94.

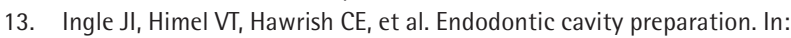
Ingle JI,Bakland LK, (eds). Endodontic. 5th. BC Decker Inc 2002;752.

14. Han X, Yang H, Li G, Yang L, Tian C, Wang Y. A study of the distobuccal root canal orifice of the maxillary second molars in Chinese individuals evaluated by cone-beam computed tomography. J Appl Oral Sci 2012;20:563-567.

15. Al-Qudah AA, Awawdeh LA. Root canal morphology of mandibular incisors in a Jordanian population. Int Endod J 2006;39:873-877.

16. Boruah LC, Bhuyan AC. Morphologic characteristics of root canal of mandibular incisors in North-East Indian population: An in vitro study. J Conserv Dent 2011;14:346-350.

17. Shemesh A, Kavalerchik E, Levin A, Ben Itzhak J, Levinson O, Lvovsky $A$, et al. Root canal morphology evaluation of central and lateral mandibular incisors using cone-beam computed tomography in an Israeli Population J Endod 2018;44:51-55

18. da Silva EJ, de Castro RW, Nejaim Y, Silva Al, Haiter-Neto F, Silberman $A$, et al. Evaluation of root canal configuration of maxillary and mandibular anterior teeth using cone beam computed tomography: An in-vivo study. Quintessence Int 2016;47:19-24.

19. Han $T$, Ma Y, Yang $L$, Chen $X$, Zhang $X$, Wang $Y$. A study of the root canal morphology of mandibular anterior teeth using cone-beam computed tomography in a Chinese subpopulation. J Endod 2014; 40:1309-1314.

20. Saberi EA, Noormandipoor M, Hosseinygoosheh SM, Salaimoghadam A. Anatomical and Morphological Features of Root Canal in Mandibular Incisors. East Medicine J 2008;10:299-304.

21. Zhang LD, Wang HN, Zhu YQ. Study of the root canal characteristics of mandibular central incisors in 150 patients using cone-beam computed tomography. Shanghai Kou Qiang Yi Xue 2014; 23:601-604.

22. Scarlatescu S, Didilescu AC, Stratul S-I, Rusu D, Grigore M, Greabu $M$, et al. Root canal morphology of mandibular central incisors in a South-Eastern Romanian population: Endodontic and periodontal implications. Timisoara Med J 2010;60:280-283.

23. Lin Z, Hu Q, Wang T, Ge J, Liu S, Zhu M, et al. Use of CBCT to investigate the root canal morphology of mandibular incisors. Surg Radiol Anat 2014; 36:877-882.

24. Sert S, Bayirli GS. Evaluation of the root canal configurations of the mandibular and maxillary permanent teeth by gender in the Turkish population. J Endod 2004;30:391-398.

25. Altunsoy M, Ok E, Nur BG, Aglarci OS, Gungor E, Colak M. A cone-beam computed tomography study of the root canal morphology of anterior teeth in a Turkish population. Eur J Dent 2014;8:302-306.

Received September 30, 2017 Accepted February 5. 2018 